\title{
ANGLIKER, ERICA; TULLY, JOHN. CYCLADIC ARCHAEOLOGY AND RESEARCH. NEW APPROACHES AND DISCOVERIES. OXFORD: ARCHAEOPRESS, 2018. 362 p. ISBN: 978-1-78491-809-5.
}

Francisco de Assis Sabadini ${ }^{1}$

\section{Palavras-chaves}

Arqueologia Pré-histórica; Arqueologia Clássica; Cíclades; Insularidade

Organizado por Erica Angliker e John Tully, o livro Cycladic Archaeology and Research. New approaches and discoveries (2018) é uma contribuição ímpar no campo da História e Arqueologia das Ilhas Cicládicas. A proposta se baseia na apresentação de novos dados e novas abordagens nesta região do mundo grego. Nascida da recente tendência para a retomada dos estudos do arquipélago, a obra trata o conjunto dos dados com base nas perspectivas contemporâneas de conectividade, trocas e circulação em contextos insulares. A relevância dos assuntos trabalhados também é pautada por temas atuais, como movimentações de povos, desastres naturais, mudanças climáticas, urbanização, exploração e uso de recursos naturais.

Dentro dessa perspectiva, o livro foi organizado de modo a contemplar um leque amplo de períodos, temas e abordagens de uma mesma área geográfica, as Cíclades. Assim, os estudos dos especialistas que contribuíram para a obra estão apresentados em ordem cronológica. Após a introdução geral feita pelos organizadores, há um primeiro capítulo, também com caráter introdutório e geral sobre as potencialidades da história e arqueologia cicládica, escrito por Christy Constatankopoulou.

O restante do livro é dividido em 4 blocos cronológicos - Cíclades no Período do Bronze, Cíclades nos Períodos Arcaico e Clássico, Cíclades no Perído Helenístico e períodos posteriores, Abordagens Diacrônicas.

Na introdução da publicação, Erica Angliker e John Tully traz ao leitor as circunstâncias que têm aquecido o interesse pelo estudo da história e arqueologia das Cíclades, um processo que teve início na década de 1970. Apontam dois principais focos que desencadearam e sustentam esse

\footnotetext{
Doutorando em Arqueologia Clássica, MAE/USP. E-mail: franciscosabadini@hotmail.com
} 
fenômeno. Em primeiro lugar as recentes descobertas arqueológicas, como as de Cítnos, Ceos, Andros e Despotiko. Em segundo, as reformulações teóricas que enfatizam estudos sobre insularidade, contatos, identidades regionais e movimentação populacional.

A paisagem cicládica capta a atenção de navegantes e exploradores desde os séculos XVIII e XIX. Na introdução, é bastante reforçada a idéia de que as Ilhas Cícladicas nunca estiveram isoladas dos contextos regionais, e esse é o principal tom que orienta a obra: a apresentação de novos achados e novas abordagens que elucidem as redes integradas atemporais que conectam as ilhas das Cíclades entre si e entre outras áreas do mundo Greco-romano.

O artigo da autoria de Christy Constatankopoulou, "Cycladic history and archaeology: some thoughts", primeiro do livro, examina a história das Cíclades em diferentes momentos, com base em documentos históricos que apresentam indícios das relações sociopolíticas nas Cíclades dos períodos Clássico e Helenístico. Assuntos como, condições de vida de trabalhadores e escravos na agricultura, violência, uso e administração de propriedades rurais, leis locais, culto e religião, dependência política, vínculos comerciais e contatos religiosos Pan-helênicos são discutidos pela autora. É sem dúvida uma abordagem que expõe as potencialidades dessas fontes para o estudo das ilhas de maneira interligada localmente e externamente.

O primeiro artigo referente ao Período do Bronze, "Terracotta statues from Ayia Irini, Kea: An experimental replication", escrito por Eleni Hasaki e Rachel DeLozier, é um exemplo da contribuição da arqueologia experimental para a compreensão das técnicas e da sociedade Cicládica do Período do Bronze. O objetivo principal do artigo é compreender a tecnologia empregada na construção de estatuetas de terracota pré-históricas. O estudo combinou informações arqueológicas com a experiência de artistas cerâmicos contemporâneos para reproduzir uma réplica de uma estatueta de Ayia Irini, datada de 1500/1425 a.C. ${ }^{2}$.

Os resultados revelaram as dificuldades existentes devido à falta de conhecimento das técnicas primárias utilizadas pelos artesãos do Período do Bronze, principalmente porque as pesquisadoras só dispunham de informações visuais presentes nas peças arqueológicas, muitas das quais foram encobertas por acabamentos na etapa final das produções préhistóricas. Contudo, o estudo dessas técnicas viabilizou a reflexão a respeito da especialização dos artesãos. $\mathrm{O}$ artigo ainda conta com um

2 A peça original se encontra no Museu Arqueológico de Ceos, número de inventário 139. 
apêndice, de autoria de Bernice Jones, onde há uma proposta de recuperação dos modelos, cores e até função das decorações que representavam as indumentárias das estatuetas.

Stephanie Martin traz um estudo importante sobre os padrões de abandonos de cidades após catástrofes naturais. Neste artigo "Abandoning Akrotiri (Thera): A comparative model approach to relocation strategies after volcanic eruptions" - a autora analisa o comportamento de abandono e reassentamento dos habitantes de Acrotíri, em Tera, após a erupção do vulcão da ilha em 1625 a.C..

O estudo foi conduzido por meio de um modelo de comportamentos e respostas sociais em caso de catástrofes, elaborado com base em dados arqueológicos e geológicos coletados em vários locais do globo. Fatores que mais influenciaram na decisão de abandono e realocação no caso de Acrotíri foram o tamanho e complexidade da comunidade, contatos sociais prévios com outras cidades e a familiaridade ambiental com os novos locais de destino.

O próximo artigo, "Coming to terms with Late Cycladic II: Questions of style and stratigraphy at Phylakopi, Melos", é um importante estudo sobre caracterização e definição de estrato arqueológico, escrito por Jason W. Earle. A tônica do artigo se concentra na discussão da caracterização do estrato arqueológico referente ao Cicládico Recente II (1450 a 1300 a.C.). Recupera, para tanto, a discussões do início do século XX sobre o sistema de classificação empregado nas Cíclades, derivado da sequência cerâmica de Cnossos. Segundo o autor, mais dados precisam ser coletados e analisados para que o estilo cerâmico do Cicládico Recente II seja bem caracterizado. Ele se mantém relutante em afirmar a existência de um estilo cerâmico Cicládico Recente II bem definido, pois é muito parecido com o estilo precedente Cicládico Recente I e com a cerâmica contemporânea do Creta, havendo ainda uma lacuna a ser preenchida nesse campo.

O primeiro artigo que abre o bloco cronológico referente aos períodos Arcaico e Clássico foi escrito por Michael J. Knight e Lesley A. Beaumont e traz para o debate um problema antigo e também contemporâneo: abastecimento de água. Em "Water supply and climate change at Zagora on Andros: New approaches and perspectives on the Early Iron Age Cyclades", os autores combinam dados arqueológicos e climáticos, somados a modelos de coleta e vazão de água em reservatórios e fontes para compreender como a população de Zágora, em Andros, lidou com abastecimento de água durante a ocupação do Período Geométrico (900 - 700 a.C.), frente a dificuldades climáticas e escassez de recurso hídrico. 
A contribuição de Aenne Ohnesorg e Katarina Papajanni, com o artigo "The sanctuary of Despotiko (Cyclades, Greece) The Building with Channel and other enigmatic structures", traz informações sobre o complexo do santuário de Apolo, no sítio arqueológico Mandra, ilha de Despotiko, que possui construções do século VIII ao V a.C.. Os autores concentram na descrição de uma construção do Período Arcaico, denominada "Construção com canal", na parte sul do santuário. Todo o complexo possui diversas instalações que poderiam ter sido utilizadas para armazenamento de animais e bens, cisternas, áreas para drenagem, fornos e canais por onde água fluía.

A grande questão é referente à real função deste espaço. Os autores acreditam, com base apenas na interpretação das estruturas, uma vez que nenhuma construção semelhante é conhecida na literatura, que a instalação possuía fins práticos, possivelmente um local relacionado à produção de alimentos.

O santuário de Despotiko, sítio de Mandra, continua a ser o contexto para o artigo escrito por Alexandra Alexandridou, "The 'Lady of Despotiko' reconsidered: Cult image or Cult utensil.

O objetivo do artigo é discutir a função de uma estatueta feminina de terracota encontrada durante escavações realizadas na Construção $\mathrm{A}$, em 2001 e 2002. A área da Construção A parece ter sido um local de culto desde o Período Geométrico, onde as construções, visíveis ainda hoje, foram edificadas posteriormente, durante o século VI a.C.. "Pepina", como é conhecida a peça, estava em um depósito junto a vasos e itens de metais, datados do Período Arcaico. A autora analisa a peça por meio de comparações com outras estatuetas semelhantes e iconografias em vasos de outros contextos Cicládicos e áticos para propor uma datação entre 675 e 650 a.C., e proveniente da ilha de Paros. Alexandra Alexandridou conclui que se tratava de um suporte para vaso e não a representação de uma deidade, mas uma sacerdotisa ou mortal comum, produzida especificamente para o santuário de Despotiko.

Dimitris Paleothodoros faz um estudo sobre a distribuição e recepção de vasos áticos de figuras negras nas Cíclades entre 600 e 450 a.C. em seu artigo "The import of Attic Black figure vases in the Cyclades". O autor traz uma síntese importante do material publicado, com informações de datação, tipologia e locais de achado. Os dados elencados sugerem que as Ilhas Cicládicas atuaram como mercado bem estabelecido para a Ática desde o segundo quartel do século VI a.C.. Entretanto os consumidores optaram por um número limitado de formas, provavelmente relacionadas a atividades de culto. 
O artigo escrito por Yannos Kourayos, Robert F. Sutton e Kornilia Daifa, "Miltiades on Paros: New evidence from Despotiko", é um exemplo de como a História e a Arqueologia podem contribuir juntas para o entendimento do passado. Os autores publicam evidencias arqueológicas que sustentam passagens de fontes históricas, principalmente Heródoto, a respeito do ataque em Paros promovido por Milcíades, após a guerra contra os persas. As evidencias materiais de tal ataque são perceptíveis nas destruições e reconstruções ocorridas no Santuário de Apolo, no sítio de Mandra em Despotiko - ilha que estava sob controle de Paros - em 490/489 a.C.. Essas evidências arqueológicas, somadas às narrativas antigas, são indicadores fortes de que as destruições causadas no santuário da ilha de Despotiko foram provocadas pela ação dos Atenienses, sob ordens de Milcíades, em resposta ao apoio dado por Paros aos persas durante a Primeira Guerra Médica. Tal retaliação, concluem os autores, só pode ter ocorrido entre 490 e 489 a.C..

No artigo "The cult topography of Paros from the 9th to 4th Century BC: A summary", escrito por Yannos Kourayos, Erica Angliker, Kornilia Daifa e John Tully, os autores fazem uma importante análise topográfica atualizada dos santuários de Paros, integrando para tal feito evidências de diferentes tipos. O resultado dessa empreitada pode ser conferido na grande quantidade de detalhes e na cronologia dos santuários que parte do Período Geométrico e alcança o Helenístico. Há apresentação de dados ceramológicos, arquitetônicos, posição dos santuários, disposição interna dos templos e as práticas de culto, revelando a continuidade na topografia de culto e santuários, além da ligação entre a religião e urbanização.

Em "From the Hellenistic sculpture of Seriphos and Siphnos", temos a abertura da subdivisão referente ao Período Helenístico e posterior. A autora, Anna Maria Anagnostopoulou, contribui com uma análise estilística da produção de estátuas femininas do Período Helenístico de Sérifos e Sifnos e compara-as com exemplares de outras regiões para o estabelecimento de correlações estilísticas e cronológicas. O estudo conclui que as estátuas dessas ilhas eram feitas em mármore branco, proporções inferiores ao tamanho humano, o que facilitava o transporte e diminuía os custos. A produção se estendeu do final do Período Helenístico até começo da Era Romana na Cíclades, direcionadas à função dedicatória ou decorativa em espaços internos ou externos, públicos ou privados. Peças inacabadas podem indicar a presença de uma oficina em Sérifos. Por outro lado, a multiplicidades de características estilísticas são sugestivas de laços artísticos com outros centros, como Delos, Rodes, Samos e Ásia Menor, algo possível para uma oficina instalada no ambiente cosmopolita dessas ilhas. 
O artigo "Panathenaic amphorae in Delos and Rhenea in the Hellenistic period", de Gilberto da Silva Francisco, analisa os múltiplos significados que as ânforas Panatenaicas - tipo específico de vaso decorado que armazenava óleo para ser ofertado como prêmio nas festas Panateneias podiam assumir durante o Período Helenístico. Mesmo após o fim da relação direta de influência religiosa, administrativa e econômica ateniense sobre Delos e Rhenea, as festividades locais assumiram certas características continentais, como a utilização e a referência às ânforas Panatenaicas. Segundo o autor, as ânforas produzidas em Atenas passavam por Delos, onde decorações em mosaicos e afrescos podem indicar a casa de atletas locais vencedores dos prêmios, para posteriormente serem depositadas em Rhenea como oferenda a Héracles. Assim, é possível pensar em uma rede que interligava as ilhas a Atenas por meio da memória atlética e de cultos.

No artigo intitulado "Parian marble in Koan statuary and utilitarian artifacts of the Hellenistic and Roman period. Finds at the sanctuary of Apollo at Kardamaina (ancient Halasarna) on Kos", os autores, Georgia KokkorouAlevras, Eirene Poupaki, Dimitris Tambakopoulos e Yannis Maniatis, buscam identificar a proveniência do mármore utilizado em esculturas e objetos encontrados nas escavações do santuário de Apolo, cronologicamente situado entre os século III e II a.C., e no posterior assentamento bizantino, estabelecido sobre o antigo templo, em Halasarna (Kardamaina), Cós, Dodecaneso. Os resultados, obtidos por métodos arqueométricos, microscópicos e macroscópicos, aplicados em fragmentos de estátuas e objetos de mármore, indicam que a maior parte do mármore utilizado em Halarsana é proveniente de Paros. Assim, os autores concluem que a mármore bruto de Paros era esculpido em oficinas locais, o que indica o grande apreço pela rocha pariana e a disposição da elite local em mobiliar riquezas para a importação. As técnicas e análises arqueométricas utilizados neste artigo são exemplo da importância do uso de tais dados em estudos de proveniência e localização de centros de produção.

O processo de cristianização das Cíclades é o assunto do artigo "The Cyclades in the late antique period. Churches, networks and Christianization", escrito por Rebecca Sweetman, Alice Devlin e Nefeli Pirée Iliou. A estratégia adotada pelas autoras foi a de sistematizar dados topográficos, funerários, arquitetônicos e epigráficos relativos às igrejas durante a Antiguidade Tardia (400 - 700 d.C.). As informações reunidas revelaram estratégias adotadas durante a cristianização do arquipélago, como a preferência pela construção das igrejas em áreas próximas a antigos santuários pagãos, construção de igrejas em áreas bastante movimentadas e um processo que parece ter se iniciado por redes que conectavam as 
populações insulares a outras áreas da Grécia. Posteriormente, contudo, este processo adquiriu características locais, fazendo com que igrejas fossem erigidas em áreas mais remotas.

Em "The Harbour of Minoa Amorgos during the Roman imperial period", Giorgos Gavalas recupera o debate: as Ilhas Cicládicas devem ser interpretadas como uma unidade ou como independentes entre si? A opinião do autor sobre esta questão é respondida ao estudar a importância do porto de Minoa na ilha de Amorgos para as redes romanas de trocas nas Cíclades entre os séculos II e IV d.C.. Ele organizou, para tanto, um sumário topográfico e de desenvolvimento urbano da região do porto. Assim, construções reveladas durante anos de escavações indicam a presença de oficinas, fornos, fábricas de vidro, banhos públicos, santuários, habitações luxuosas, muralhas e cemitérios nos arredores do porto. Situadas cronologicamente entre o final do século II e VII d.C., essas construções evocam a imagem de um centro urbano planejado e em desenvolvimento na região do porto antigo de Minoa, além de revelarem que a ilha desempenhava um papel significativo para a ligação entre Leste e Oeste do Mediterrâneo durante o Período Imperial Romano.

Os artigos subseqüentes fazem parte da última divisão do livro, as Abordagens Diacrônicas. O artigo "The Irakleia Caves Exploration Project and the importance of cave research for the archaeology of the Cyclades: A brief note", escrito por Fanis Mavridis, Žarko Tankosić e Antonis Kotsonas, abre o último bloco. Neste artigo a preocupação dos autores é demonstrar a importância do estudo de cavernas para a exploração arqueológica, apresentando os resultados parciais de um projeto intitulado "Irakleia Caves Exploration Project". O projeto busca contribuir para o mapeamento e estudo de cavernas localizadas em Heracleia, nas Cíclades, uma vez que essas formações naturais foram pouco exploradas nesta região se comparado com outras do Egeu. As questões propostas pelo projeto abrangem diferentes períodos - Neolítico a Período Romano - e usos das cavernas, seja para habitações ou rituais, em comparação com outras regiões, principalmente com Creta. É importante salientar que o artigo acrescenta ao estudo da dinâmica e uso das cavernas nas Cíclades o componente da insularidade que permeia a proposta do livro, trazendo uma perspectiva diferente e inovadora em relação ao estudo de cavernas em outras regiões egéias.

Em "Votive and honorific monument offering practce(s) in Delos. Evolution of a social practice in Apollo's sanctuary froam archaic times to the Roman era", escrito por Frederic Herbin, temos um estudo das inscrições dedicatórias presentes em base de estátuas associadas ao santuário de Apolo, em Delos. 
O objetivo principal do autor é compreender a evolução da prática de oferendas de estátuas no santuário, inserida no contexto maior da história política e social de Delos em seus períodos específicos: Arcaico, Clássico, Independência de Delos, Colônia de Atenas e Romano. As inscrições apresentam algumas informações, como nomes e origem dos doadores e receptores das estátuas votivas ou honoríficas. Em alguns casos há o nome do artista responsável pela criação e a circunstância da doação. Ao longo do artigo o autor apresenta exemplos de inscrições nos períodos mencionado acima, sempre fazendo o paralelo com o contexto político e social da época, onde se observa a mudança no número, tipo e propósito dos doadores.

No artigo "Ancient Paros: New evidence for its topographical development in light of rescue excavations", de Yannos Kourayos, o leitor pode ter uma dimensão do desenvolvimento da antiga pólis de Paros ao longo de séculos. Os dados são oriundos das antigas escavações do século XIX e de 35 anos de escavações de resgate promovidas pela Eforia de Antiguidades das Cíclades. Ao longo do artigo são apresentadas informações das principais estruturas e achados, como habitações, oficinas, templos, muralha, cemitério e enterramentos. Todos os dados resultados das escavações de salvamento que trouxeram à tona elementos da pré-história, assim como dos períodos históricos.

No artigo de Lydia Palaiokrassa Koptisa, "New evidence from the agora of ancient Andros. The city of Andros", temos a disposição novos dados referentes às escavações da antiga cidade homônima da ilha, Andros, fundada em 700 a.C.. Os dados são bastante variados, com destaque a estruturas, como templos, igrejas, muralha e construções do século V a.C. ao século XX d.C.. Tais informações explicam alguns dos usos e da dinâmica da área da Ágora ao longo da história e do desenvolvimento urbano de Andros.

No artigo "Sensory study of vision in the panegyris of Delos: Seeing the sacred landscape and sensing the god", o autor Matteo F. Olivieri, busca reconstruir a experiência sensorial de fiéis que participavam de rituais na ilha de Delos. A abordagem segue a metodologia dos estudos sensoriais e focaliza principalmente na experiência da visão e em como este sentido criou uma imagem cultural do culto deliano. $\mathrm{O}$ autor procede utilizando relatos e dados sobre as impressões visuais durante a viagem por mar até Delos, da paisagem de Delos, das formações naturais da ilha, das marcas antrópicas e dos rituais. Tais impressões criaram diferentes significados, conceitos e sentimentos ao longo de diferentes períodos. 
Alexandra S. Sfyroera, em seu artigo "Naxos, the largest Cycladic island with a single polis. A survey through ancient times", combina dados literários e epigráficos com arqueológicos que indicam a existência de uma única pólis em Naxos durante a pré-história e a Antiguidade. A pólis de Naxos se desenvolveu com habitação contínua desde o Período do Bronze, mas a urbanização e a organização espacial se deram durante o Período Geométrico, passando, posteriormente, durante o Período Arcaico, pelo estabelecimento de construções religiosas monumentais e estruturas de grande valor cívico. O processo continuou durante os Períodos Clássico e Helenístico, entretanto a pólis começou a declinar como estado durante o Período Romano, perdendo sua organização.

O último artigo do livro, intitulado "The island of Pholegandros and the graffiti of Chrysospilia cave", de Vivi Vassilopoulou, traz uma síntese da exploração e dos grafites encontrados na caverna de Chrysospilia, na ilha de Folegandros, em 1987 e 1989. Há muitos grafites escritos ainda na Antiguidade, com nomes, datas e até origens de antigos visitantes. Os nomes estão escritos em Grego antigo, a maioria são de nomes masculinos e datam do Período Arcaico até o Romano. O autor interpreta o espaço como um local de rituais de cerimônias religiosas na antiguidade, aparentemente único até o momento, pois não há referências e publicações que relatem locais semelhantes. Contudo, mais pesquisas são necessárias para lançar luz quanto ao uso e ao período de atividade na caverna durante Antiguidade.

O livro Cycladic Archaeology and Research. New approaches and discoveries é uma excelente opção para todos que desejam explorar os muitos contextos arqueológicos e históricos das Ilhas Cicládicas. A obra oferece ao leitor dados e abordagens atualizadas, apresentando a produção científica de especialistas de diferentes nacionalidades. Questões contemporâneas que encontram paralelos no passado, como identidade, imigração, uso de recursos naturais, mudanças climáticas, subjetividade, propriedade, trabalho, dependência econômica e política, conflitos, conectividade, integração, religião, urbanização, entre outras, estão distribuídas nas páginas do livro sob variadas perspectivas.

\section{Referências bibliográficas}

ANGLIKER, Erica; TULLY, John (Orgs). Cycladic Archaeology and Research. New Approaches and Discoveries. Oxford: Archaeopress, 2018. 